\title{
Wildlife conservation and reproductive cloning
}

\author{
William V Holt, Amanda R Pickard and Randall S Prather ${ }^{1}$ \\ ZSL Institute of Zoology, Regent's Park, London NW1 4RY, UK and ${ }^{1}$ University of Missouri-Columbia, Columbia, \\ Missouri 65211, USA \\ Correspondence should be addressed to W V Holt; Email: Bill.Holt@ioz.ac.uk
}

\begin{abstract}
Reproductive cloning, or the production of offspring by nuclear transfer, is often regarded as having potential for conserving endangered species of wildlife. Currently, however, low success rates for reproductive cloning limit the practical application of this technique to experimental use and proof of principle investigations. In this review, we consider how cloning may contribute to wildlife conservation strategies. The cloning of endangered mammals presents practical problems, many of which stem from the paucity of knowledge about their basic reproductive biology. However, situations may arise where resources could be targeted at recovering lost or under-represented genetic lines; these could then contribute to the future fitness of the population. Approaches of this type would be preferable to the indiscriminate generation of large numbers of identical individuals. Applying cloning technology to non-mammalian vertebrates may be more practical than attempting to use conventional reproductive technologies. As the scientific background to cloning technology was pioneered using amphibians, it may be possible to breed imminently threatened amphibians, or even restore extinct amphibian species, by the use of cloning. In this respect species with external embryonic development may have an advantage over mammals as developmental abnormalities associated with inappropriate embryonic reprogramming would not be relevant.
\end{abstract}

Reproduction (2004) 127 317-324

\section{Introduction}

Nuclear transfer technology, known popularly as cloning, whereby new individuals are created in the laboratory from the nuclear DNA of other individuals, has a history that extends back to the late nineteenth century when Driesch (1892; cited by Di Berardino 2001) produced sea urchin larvae from isolated blastomeres. Although nuclear transfer did not create these larvae, they represented 'proof of principle' that early-stage embryonic cells had the capacity to develop autonomously into a whole individual. Di Berardino (2001) describes this and other examples in a review that covers the development of embryological and associated studies in cloning technology from those significant early beginnings to the production of the first cloned mammals. Interestingly, the review also covers the development of cloning technology in insects, amphibians and fishes, species that rarely enter the public debate on cloning in species conservation. The public and media often equate conservation solely with saving endangered mammals such as the giant panda, forgetting that mammals are an 'ethnic minority' among vertebrates. Reid \& Hall (2003) recently compared the number of described fish species (25157) with the equivalent numbers belonging to other vertebrate classes (i.e. birds (9040), reptiles (6458), mammals (4629) and amphibians (4222)). Thus mammals comprise just under $10 \%$ of the total number of vertebrates, but seem to gain $90 \%$ of the attention. Any assessment of the potential role of reproductive cloning in species conservation should consider this discrepancy. Factors that govern the desirability, feasibility and practicality of cloning vary among different classes of vertebrates, depend upon the peculiarities of the biological systems themselves, the type of species under threat and even the chances of obtaining suitable funding.

\section{Objectives of conservation and the role of cloning}

This review does not aim to examine the technical details involved in cloning methodology as plenty of such reviews have already been written. Instead, it considers the conservation-related goals that this technology would, or could, serve. As the detailed biology of cloning in most species is unknown at the present time, the authors do not aim to consider the detailed advantages, disadvantages and biological implications of every potential cloning application; that would require virtually unlimited amounts of text. Moreover, in line with the objectives of review papers in this journal, this review is aimed at a wide audience who are not necessarily experts in either wildlife conservation or cloning; species-specific details 
of cloning are therefore less relevant in this context than the general principles.

Simplistically, cloning is one of several ways of increasing the number of individuals within a population. Clearly, natural breeding is the preferred method for thriving populations; but by definition these are not of conservation concern. However, when populations of free-living species are found to be in decline, conservation biologists begin to seek methods of slowing or reversing the threatening processes. Many such threats exist, including habitat loss through human activity, hunting and over-fishing, effects of pollution on fertility and fecundity, predation by introduced species or, indeed, poor diet through loss of prey species. In a few cases these threats can be alleviated, but this may require the development of national and international policies that support the conservation goals. Reproductive technologies may then provide support, usually by assisting with genetic management. An important common aim of conservation breeding programmes, with or without the use of assisted reproduction, is the avoidance of inbreeding depression and the associated exposure of rare, and often deleterious, alleles. The Mauritius kestrel provides a good example of successful reintroduction without assisted breeding; the population declined to about nine individuals in the early 1970s, four were reintroduced to the island of Mauritius, and the population is now estimated at $700-800$ (Groombridge et al. 2000). Genetic analyses have revealed that, compared with pre-crash individuals, the population is now extremely homogeneous and therefore poorly equipped to adapt to environmental changes. Nevertheless, this has so far not proved to be a problem. The black-footed ferret represents an example where assisted reproduction played a major part in the recovery and survival of a species. This species declined almost to the point of extinction in the 1970s-1980s, but 18 animals were captured by the Wyoming Game and Fish Department (Thorne \& Oakleaf 1991). A species recovery strategy was developed in which assisted reproduction within a captive-breeding group played a key role. The captive-breeding programme proved such a success that reintroductions have now been possible in several states of the USA (for review see Howard et al. 2003).

How could nuclear transfer have helped with these two examples? Populations with low numbers of individuals possess minimal genetic variation. It is therefore desirable to avoid further losses of diversity. A subsequent generation resulting from natural breeding or artificial insemination (Al) would contain some, but not all, of the genetic variability of its parents. Losses would occur if any of the individuals failed to breed, a strong possibility with small populations. If cloning was guaranteed to be $100 \%$ successful, a good strategy might be to clone every individual (not impossible if the population size is only 9-18), then allow the offspring to mature and breed naturally. The probability of losing genetic diversity would then be reduced, especially if each parent gave rise to more than two identical copies of itself. Thus, an interesting and novel theoretical principle in animal conservation emerges, where individuals are effectively induced to reproduce asexually, somewhat like plants, thereby improving the long-term fitness of the species through the retention of genetic diversity.

It is important to ask, however, to what extent this could be achieved, if at all? Current success rates with nuclear transfer in mammals are very low (less than $0.1-5 \%$ of reconstructed embryos result in a live birth (Di Berardino 2001, Wakayama \& Yanagimachi 2001). Therefore, between 20 and 1000 nuclear transfers would need to be performed to achieve one viable offspring. Assuming, for example, that oocyte recovery from two black-footed ferret females could be justified, it is most likely that two or three oocytes might be recovered, rendering the realistic chance of obtaining a single offspring somewhere between 0.0006 and $0.3 \%$; vanishingly small. To date the cloning of birds has not been accomplished; therefore the Mauritius kestrel example could not have been addressed at all with this technology.

This suggests that applying cloning technology to highly endangered species is hopelessly optimistic given current efficiencies. However, should the idea of cloning be ruled out altogether? More embryos and births could be expected when dealing with larger populations. The best way to maximise success might therefore be to concentrate on poly-ovulatory, litter-bearing species provided that a minimum number of viable concepti were available to sustain pregnancy to term. This would immediately exclude many of the larger mammals, including the giant panda that only ovulates one or two oocytes per year (Kleiman 1983, Hodges et al. 1984). Nevertheless, this is such a popular choice of candidate species that a special research programme has been initiated in China. Paradoxically, this argument leads towards using cloning technologies for endangered rodents, where other more traditional assisted reproductive technologies have been largely overlooked. Although there are 330 endangered rodent species (International Union of Conservation of Nature and Natural Resources (IUCN) 2002), techniques such as $\mathrm{Al}$, semen freezing and embryo transfer have not been applied successfully to any of them. It would be feasible to collect and cryopreserve ovarian slices from many individuals of such species, and prepare fibroblast cell lines from muscle or skin, with the expectation that cloning might be ultimately successful. Offspring representing the genetic variability of the founder populations could then be regenerated using methods allied to those currently being developed for the laboratory mouse. This implies that any attempt to clone such species should be approached on a grand scale, where sufficient numbers of offspring could be generated to maintain a genetically diverse population. In this case the level of genetic diversity could never exceed that of the original population and would undoubtedly be less. 


\section{Does cloning have a place in conservation?}

The low conception rates currently associated with cloning cannot be cited as justification for not embracing this technology; while pragmatic, to do so is disingenuous and misleading. Dramatic improvements in the success rate achieved with, for example, ungulates would remove that particular argument, but would conservation biologists then rush to include cloned gazelles, oryx and addax in their breeding programmes? As many conservationists are still suspicious of reproductive technologies, it is unlikely that cloning techniques would be easily accepted. Individuals involved in field conservation often harbour suspicions that hi-tech approaches, backed by high-profile publicity, would divert funding away from their own efforts. This may be true, but often the sources of funding would not necessarily compete with each other.

A major practical objection to using cloning technology in wildlife conservation is a fundamental lack of information about the basic physiology of endangered species. While it is obvious that the species requiring most urgent protection and conservation are those that are considered 'endangered', it may be less obvious to some that these are the very same species for which the least background physiological knowledge exists. Reliable protocols for inducing oocyte recruitment, development and maturation simply do not exist in most cases. Where intensive efforts have been made to develop such protocols, these are often far more complex projects than originally envisaged. For example, approximately a decade ago a focused research programme was initiated that aimed at developing $\mathrm{Al}$ techniques for snow leopard and clouded leopard (Barone et al. 1994, Brown et al. 1995, Swanson et al. 1996). Breeding leopards by the use of in vitro fertilisation and embryo transfer (IVF-ET), or simply by $\mathrm{Al}$, is of interest because behavioural incompatibilities often preclude the use of natural breeding. To date, using exogenous hormones to control the timing of ovulation and the quality of oocytes in leopards has presented a major problem. However, while progress has undoubtedly been made, the research can only be undertaken slowly and on a modest scale because, being endangered, research animals are not readily available. In fact, the regulatory authorities in the United Kingdom frown on research projects that use insufficient subjects, because animal welfare is then sacrificed for the sake of experimental data that may be invalid.

The same principles would apply to a cloning project. However, if suitable oocytes were eventually obtained for nuclear transfer experiments, questions about the viability and fitness of resultant offspring would still need investigation. Therefore, the acquisition of scholarly knowledge about a species' reproductive system, together with a detailed understanding of cellular and developmental processes peculiar to that species, is a valuable exercise in itself but can only be undertaken within focused research programmes. Irrespective of any cloning objectives, scientific benefits are obtained from such studies. In most cases, however, these projects are difficult to fund unless the species in question is particularly unusual and the study would lead to novel scientific insights.

A significant shortcoming of nuclear transfer technology in its current state is the prospect that resultant offspring will suffer from some degree of abnormality. Since the first sheep were produced by nuclear transplantation using cultured cells as sources of nuclei (Campbell et al. 1996, Wells et al. 1997, Wilmut et al. 1997) many studies have revealed that cloned mammals suffer from developmental abnormalities. These include extended gestation, large birthweight, inadequate placental formation and histological defects in most organs, including kidney, brain, the cardiovascular system and muscle (Hill et al. 1999, Barnes 2000, Chavatte-Palmer et al. 2000, De Sousa et al. 2001, Hammer et al. 2001, Renard et al. 2002). These effects have been attributed to inefficient reprogramming and imprinting of nuclear DNA (Young \& Fairburn 2000, Humpherys et al. 2001, Chung et al. 2003), a process that occurs naturally during gametogenesis and early development, and governs whether certain genes are expressed from the maternal or paternal chromosomes.

\section{Cloning as a conservation support tool}

Various arguments in favour of cloning programmes for various groups of extant and extinct species have been proposed (for reviews and proposals see Ryder \& Benirschke 1997, Lanza et al. 2000, Wells 2000, Stone 2001, Ryder 2002, Critser et al. 2003). Proponents often cite the massive species declines that are currently occurring and recommend taking any suitable actions that might reverse the trend. These arguments mirror the view that established reproductive technologies, such as $\mathrm{Al}$ and IVF-ET, are useful for supporting living populations (Holt et al. 1996, Holt \& Pickard 1999, Watson \& Holt 2001). Certainly, focused programmes could help with genetic management and the maintenance of genetic diversity. Semen banks could be used for Al, although the detailed methodologies for insemination timing and semen cryopreservation must be optimised for each species. These banks of frozen semen should be considered as supporting genetic management strategies whose primary role is to maintain genetic diversity within populations of limited size. In principle, frozen semen can be transported within and between countries, thus removing part of the physical barrier causing the fragmentation and isolation of small populations. This function of a genetic resource bank (GRB) provides an additional genetic benefit in the sense that a genetically important male can still be used within a breeding programme long after his death.

The theoretical benefits of this approach have yet to be matched in practice but progress is being made. Useful GRBs for a number of species are being established across the world and some breeding programmes incorporate frozen semen into their strategies. The black-footed ferret 
is the best example, but a cheetah breeding programme in Namibia is now using frozen semen (http://www.cals.ncsu. edu/agcomm/magazine/winter03/catsdogs.htm) whileGRBs for koalas in Australia (Johnston \& Holt 2001) and gazelles in Spain and Saudi Arabia (Pickard et al. 2001, Holt et al. 2002) are being established.

Applying similar logic, several international groups have established banks of frozen tissues and cell lines (for example, the Center for Reproduction of Endangered Species, San Diego), in anticipation that these will provide the genetic resources for cloning programmes aimed at supporting declining populations. This differs from restoring an extinct species and is, in principle, a sensible idea. At the very least, banks of cells and tissues are useful resources for molecular studies of evolution and phylogeny. Considerable caution should be exercised, however, before animals produced from such materials are considered to make a positive and direct contribution to the genetic well-being of a population. Inadequate nuclear reprogramming and phenotypic abnormalities may reduce, rather than support, the fitness of the whole population. However, in some species these abnormal phenotypes are not transferred to subsequent offspring (mice, Shimozawa et al. 2002; pig, Prather et al. 2003). This observation leads to one defence of cloning as a potential conservation tool; provided the limitations of these first-generation effects are recognised, it should be possible to breed a second generation of healthy individuals (Fig. 1). Using this argument raises a number of welfare and ethical concerns that may eventually take precedence over the biological arguments. Some of the first generation of cloned offspring would have to be kept in a managed facility or zoo, to meet their husbandry and veterinary needs. This facility would almost certainly attract adverse public attention, and even material damage from animal rights activists, incurring additional costs by virtue of its good intentions. The occurrence of first-generation abnormalities differs between species, fewer occurrences in pigs and mice having been noted than in cattle and sheep, therefore the potential value of cloning for

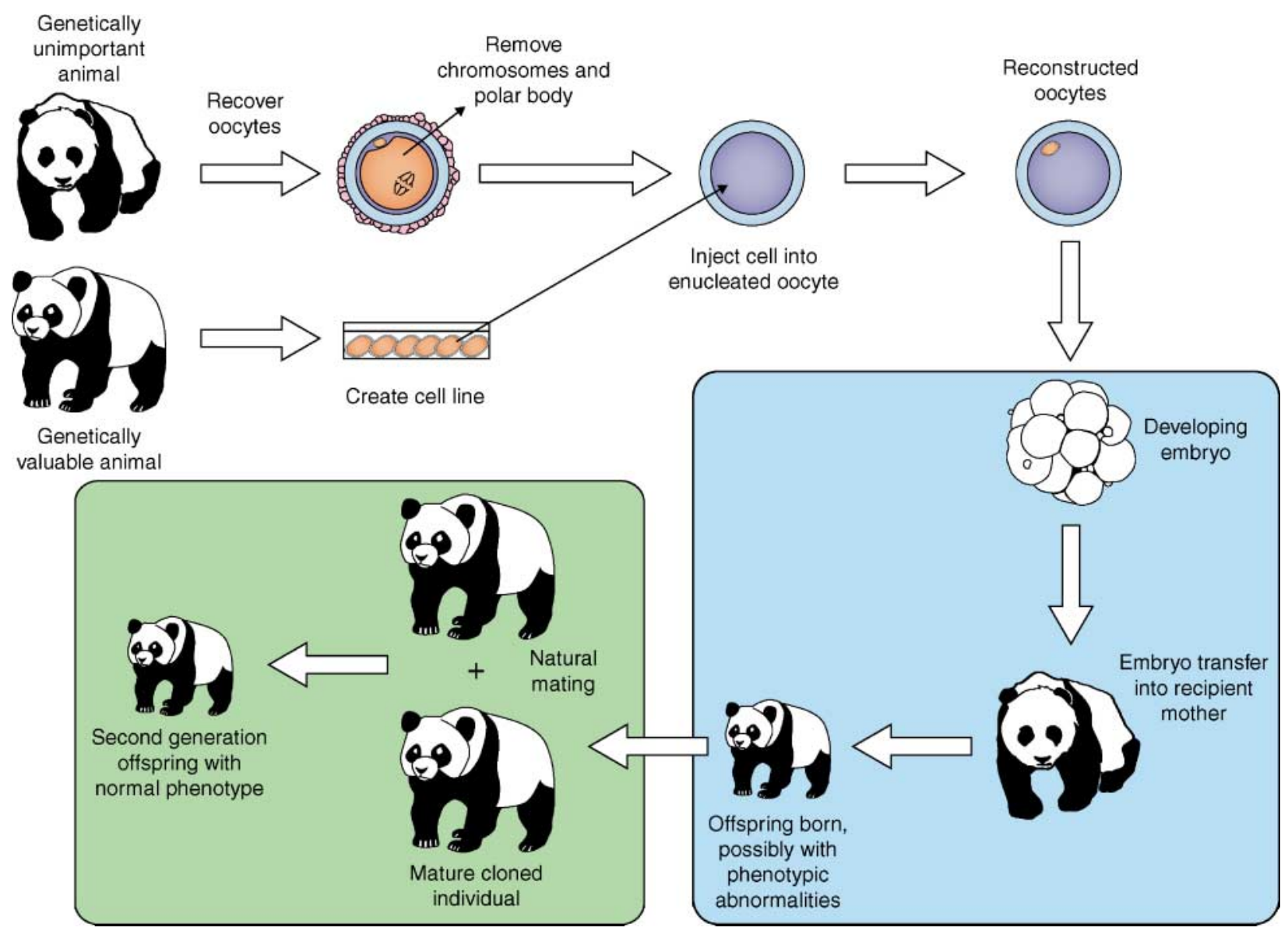

Figure 1 Schematic diagram showing the steps by which a genetically valuable animal (nucleus donor) could be cloned. In this example, a female of the same species serves as an oocyte donor, thereby eliminating problems of mitochondrial heteroplasmy in the resultant reconstructed embryo. The diagram also points out that while a cloned offspring may exhibit phenotypic abnormalities, these are not necessarily evident in a subsequent generation produced through natural breeding. 
conservation may also be species-specific. For the most endangered species this theoretical argument is unsustainable in practical terms, because the background research required to establish the absence of first-generation abnormalities could not be undertaken. These arguments should not, however, prevent the establishment of cell and tissue collections for wildlife species. If techniques eventually become simpler and more reliable these resources could be used in the long-term; this strategy is currently being used in attempts to prevent extinction of the Northern hairy-nosed wombat in Australia (Wolvekamp et al. 2001).

Several attempts at cloning exotic or endangered species have received widespread publicity (e.g. Gaur (Bos gaurus), Banteng (Bos javanicus) and Bucardo (Capra pyrenaica pyrenaica)). The distinguishing feature of these examples is that they employed trans-species cloning (Fig. 2). In these instances, the oocyte cytoplasm being used to create embryos was derived from common domesticated species (Bos taurus (cow) or Capra hircus (goat)), while the cell nucleus was from the species of interest. Trans-species clones inevitably differ from either of the parental species in their nucleo-cytoplasmic characteristics.
At the very least, mitochondria inherited from the recipient oocyte would have a major influence over functions, such as muscle development and physiology, that depend on mitochondrial gene expression. Animals resulting from these trans-specific cloning efforts would be scientifically valuable for their insights into the functional relationships involved in nucleo-mitochondria dialogue, but would not be directly useful for supporting the endangered populations.

However, when debating the relative value of first- and second-generation clones, it is useful to remember that male clones of breeding age would not transfer their mitochondria to the next generation (Sutovsky et al. 2000). This knowledge, together with the ability to identify those species that do not pass phenotypic abnormalities to the next generation, leads to an interesting conclusion. In theory, it should be possible to use trans-species cloning strategies to restore the nuclear genome of a male genetic line of particular value. This would be a highly specialised and targeted use of cloning, and would contribute directly to the maintenance of genetic diversity (Fig. 3). The same argument does not apply to the female line because mitochondria are inherited via the maternal cytoplasm.

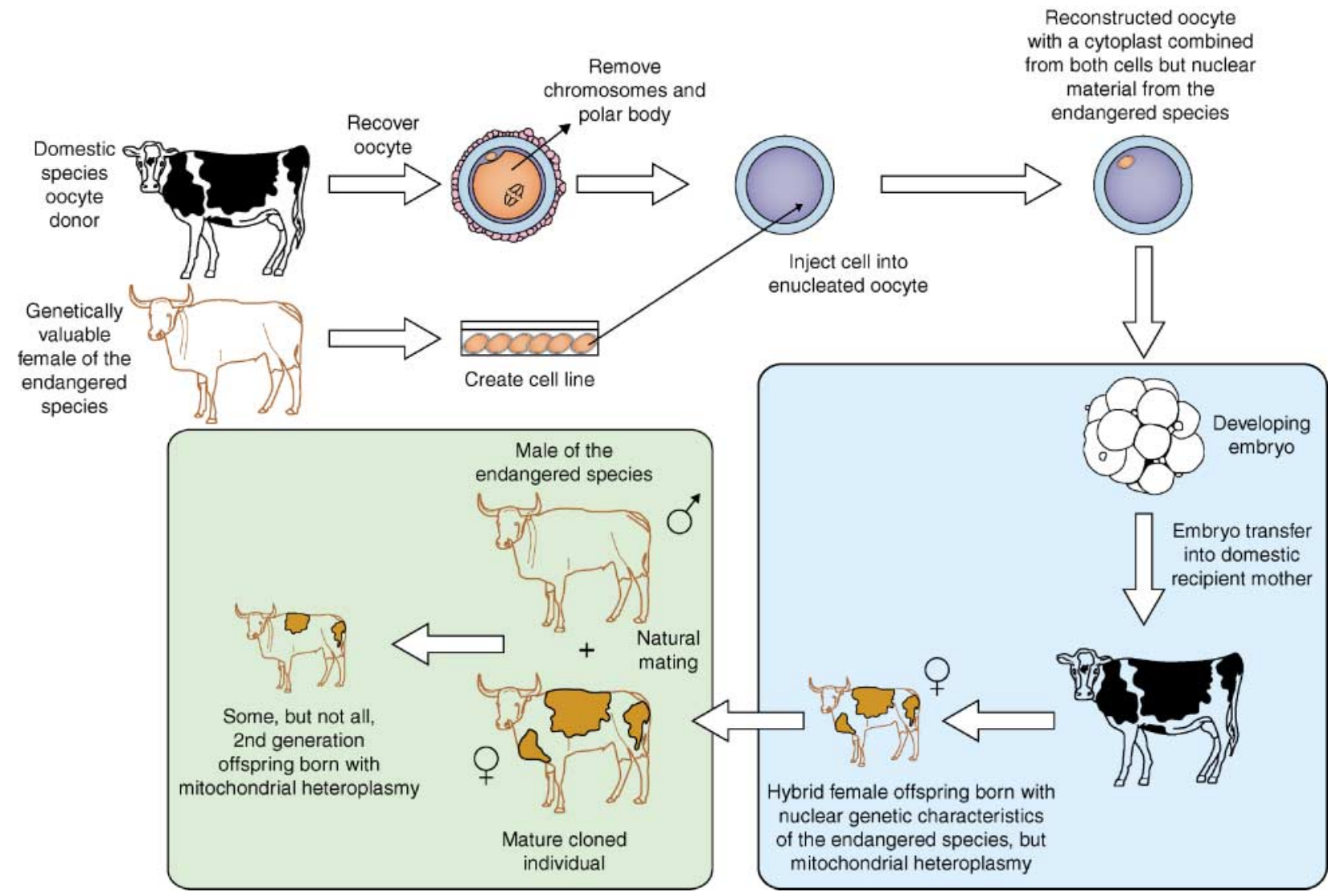

Figure 2 This example highlights the importance of considering the fate of mitochondria in relation to trans-species cloning. Here, it is envisaged that a domestic cow provides the oocyte cytoplasm, while the donor nucleus, and its accompanying cytoplasm, is derived from a female of a different species. The resultant reconstructed embryo would contain mitochondria from both species, thus being an unusual type of hybrid. If such a cloned female were to breed naturally with a male that shared its nuclear genome, the offspring would still possess mitochondria that descended from the original oocyte donor cow. 


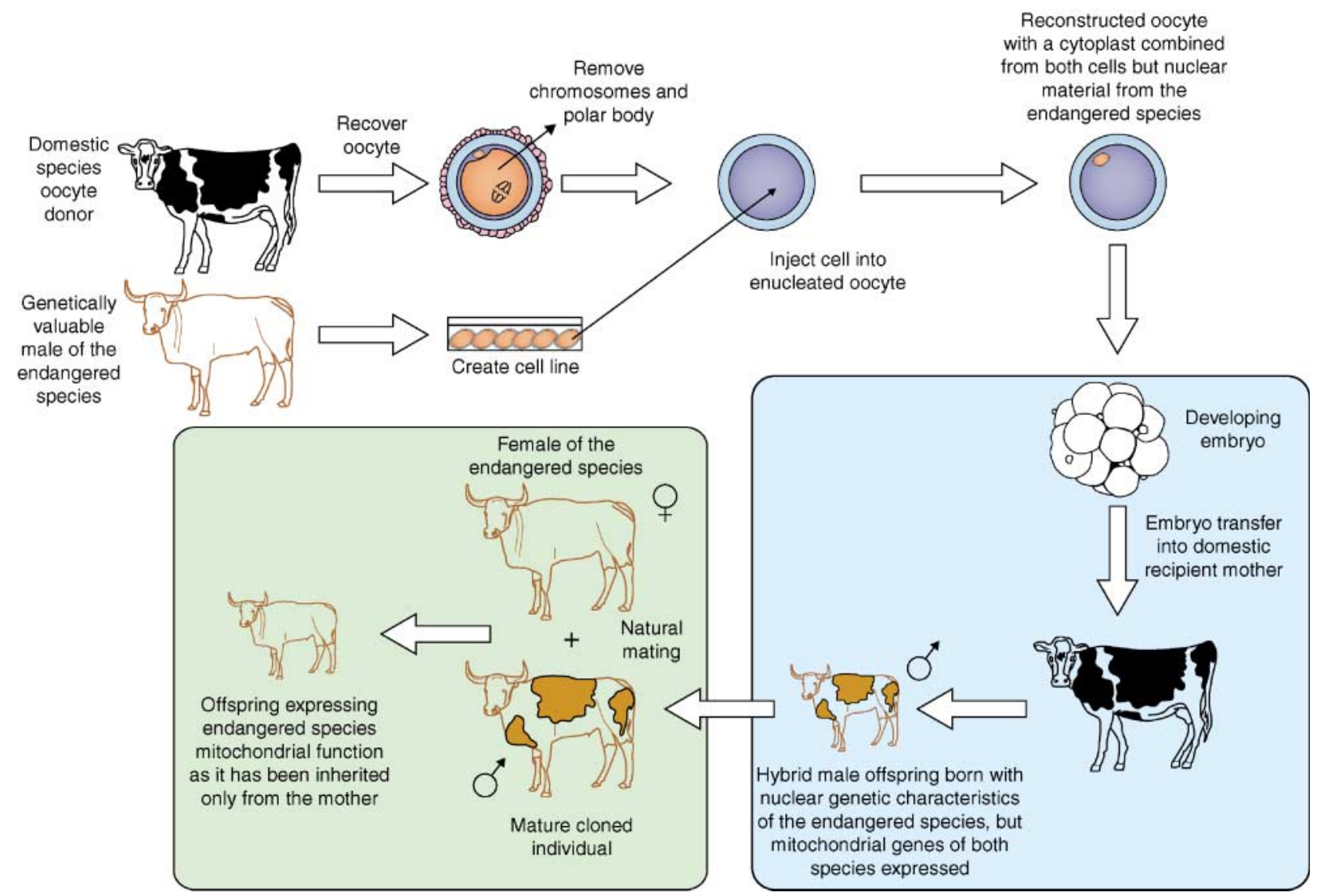

Figure 3 This example shows how the problem of mitochondrial inheritance, shown in Fig. 2, could be avoided, while still using oocytes derived from a common species such as a cow. The original donor nucleus and accompanying cytoplasm are derived from a male of the endangered species of interest. Although the reconstructed embryo and therefore the first-generation offspring would exhibit mitochondrial heteroplasmy, this could be eliminated if a cloned male offspring were to breed naturally with a female of the endangered species of interest because paternal mitochondria are not transmitted to the next generation.

As mentioned earlier, it is worth considering whether cloning technologies might be applicable to non-mammalian vertebrates. This possibility seems to have been overlooked by conservation biologists, despite the fact that amphibians (Rana pipiens and Xenopus laevis) were first cloned in pioneering experimental work during the1960s (Briggs \& King 1960, Gurdon 1962). Amphibians are globally experiencing significant decline, possibly due to emerging diseases such as chytridiomycosis and ranaviruses (Daszak et al. 1999). This phenomenon, popularly known as the 'amphibian extinction crisis' signals the urgent need for implementing protective measures. It is therefore surprising that there is a dearth of studies on methods of assisted reproduction in these species. Some research on semen collection and freezing has recently been published (Beesley et al. 1998, Browne et al. 1998, Mugnano et al. 1998), but most of this work has commenced within the last 5 years. Nuclear transfer in fish has been studied for about 40 years in China by T C Tung (quoted by Yan 2000), with two recent papers reporting successful reproductive cloning in fish. Wakamatsu et al. (2001) obtained fertile, diploid Medaka (Oryzias latipes) by transferring embryonic cell nuclei into enucleated oocytes, while Lee et al. (2002) cloned zebrafish by transferring nuclei from long-term cultured fibroblasts into enucleated eggs. Both studies had low success rates $(\leq 2 \%)$, consistent with the results in mammals. Cloning might logically be successfully applied to threatened species of fish, and it might even be relatively straightforward to mass-produce the offspring. The eggs are often produced in large quantities, sometimes thousands or millions at a time, and are physically large in comparison to mammalian oocytes. It is possible to culture fish cells in vitro, so making an extensive collection of endangered fish cell lines should perhaps be a current conservation priority. However, methods for obtaining the eggs may be the most challenging aspect of such a programme.

Fish species are extremely diverse, as are their reproductive systems. One species of molly (Poecilia formosa), for example, reproduces entirely by parthenogenesis, and occurs naturally as all-female populations. Although this process differs biologically from cloning, it is similar in some respects, being a variant of asexual reproduction. Females mate with another sympatric Poecilia species, but spermatozoa play no role in fertilisation and the female 
genome is copied in its entirety from one generation to the next. Mating simply stimulates egg development, the male does not contribute to the genome of the offspring, and all-female clones are produced (Paxton \& Eschmeyer 1998).

This extreme example underlines an important, relevant principle. While the detrimental effects of inbreeding are widely recognised as something to be avoided, the specific consequences of inbreeding differ between species. The reasons are unclear and could be a matter of chance, but they could also reflect the environment within which species have evolved. Thus a species that lives in small isolated groups may be less affected by inbreeding depression than one that is normally found in large groups, where it would be unusual to have restricted mate choice. This is relevant when considering the desirability of a cloning programme; survival and fitness of offspring may differ between species for the same reasons.

\section{Conclusions}

Biological problems associated with the cloning of mammals have stimulated considerable debate about ethical aspects of the procedure, both among scientists and the general public. Developmental biologists at the forefront of cloning research emphasise the need for caution, while encouraging continued research. Unfortunately, those few who abandon caution tend to be both highly vociferous and good at capturing media attention. Hence, a highly publicised plan to clone a Tasmanian tiger using DNA recovered from a single alcohol-fixed museum specimen has generated considerable publicity worldwide, attracted funding for the project and raised public expectations of success (Anon 2002, Meek 2002). Examples of this sort manage, however, to create the impression among the conservation community that reproductive and developmental biologists are unthinking zealots who only want to perform the latest hi-tech procedures. In an era where rapid advances in cloning technology are being made, perhaps it is more appropriate to focus on developing realistic strategies for using these methods in wildlife conservation and ensuring that scarce resources are deployed where they will be most effective.

\section{References}

Anon 2002 Reviving the Tasmanian tiger. Science 2961797.

Barnes FL 2000 The effects of the early uterine environment on the subsequent development of embryo and fetus. Theriogenology 53 649-658.

Barone MA, Wildt DE, Graham LH, Byers AP, Collins L, Barrett $S$, Byers AP, Roelke NE, Glass CM \& Howard JG 1994 Gonadotrophin dose and timing of anaesthesia for laparoscopic artificial insemination in the puma (Felis concolor). Journal of Reproduction and Fertility 101 103-108.

Beesley SG, Costanzo JP \& Lee RE Jr 1998 Cryopreservation of spermatozoa from freeze-tolerant and intolerant anurans. Cryobiology 37 155-162.
Briggs R \& King TJ 1960 Nuclear transplantation studies on the early gastrula (Rana pipiens). Developmental Biology 2 252-270.

Brown JL, Wildt DE \& Howard JG 1995 Natural versus chorionic gonadotropin-induced ovarian responses in the clouded leopard (Neofelis nebulosa) assessed by fecal steroid analysis. Biology of Reproduction 53 93-102.

Browne RK, Clulow J, Mahony M \& Clark A 1998 Successful recovery of motility and fertility of cryopreserved cane toad (Bufo marinus) sperm. Cryobiology 37 339-345.

Campbell KHS, McWhir J, Ritchie WA \& Wilmut I 1996 Sheep cloned by nuclear transfer from a cultured cell line. Nature $\mathbf{3 8 0}$ 64-66.

Chavatte-Palmer P, Heyman Y \& Renard JP 2000 Cloning and associated physiopathology of gestation. Gynecology Obstetrics and Fertility 28 633-642.

Chung YG, Ratnam S, Chaillet JR \& Latham KE 2003 Abnormal regulation of DNA methyltransferase expression in cloned mouse embryos. Biology of Reproduction 69 146-153.

Critser JK, Riley LK \& Prather RS 2003 Application of nuclear transfer technology to wildlife species. In Reproductive Science and Integrated Conservation, pp 195-208. Eds WV Holt, AR Pickard, J Rodger \& DE Wildt. Cambridge: Cambridge University Press.

Daszak P, Berger L, Cunningham AA, Hyatt AD, Green DE \& Speare R 1999 Emerging infectious diseases and amphibian population declines. Emerging Infectious Diseases 5 735-748.

De Sousa PA, King T, Harkness L, Young LE, Walker SK \& Wilmut I 2001 Evaluation of gestational deficiencies in cloned sheep fetuses and placentae. Biology of Reproduction 65 23-30.

Di Berardino MA 2001 Animal cloning - the route to new genomics in agriculture and medicine. Differentiation 68 67-83.

Groombridge JJ, Jones CG, Bruford MW \& Nicols RA 2000 Genetic analysis tells of conservation success in the Mauritius kestrel. Nature 403616.

Gurdon JB 1962 Adult frogs derived from nuclei of single somatic cells. Developmental Biology 4 256-273.

Hammer CJ, Tyler HD, Loskutoff NM, Armstrong DL, Funk DJ, Lindsey BR \& Simmons LG 2001 Compromised development of calves (Bos gaurus) derived from in vitro-generated embryos and transferred interspecifically into domestic cattle (Bos taurus). Theriogenology 55 1447-1455.

Hill JR, Roussel AJ, Cibelli JB, Edwards JF, Hooper NL, Miller MW, Thompson JA, Looney CR, Westhusin ME, Robl JM \& Stice SL 1999 Clinical and pathologic features of cloned transgenic calves and fetuses (13 case studies). Theriogenology 51 1451-1465.

Hodges JK, Bevan DJ, Celma M, Hearn JP, Jones DM, Kleiman DG, Knight JA \& Moore HDM 1984 Aspects of the reproductive endocrinology of the female Giant Panda (Ailuropoda melanoleuca) in captivity with special reference to the detection of ovulation and pregnancy. Journal of Zoology, London 203 269-278.

Holt WV, Bennett PM, Volobouev V \& Watson PF 1996 Genetic resource banks in wildlife conservation. Journal of Zoology, London 238 531-544.

Holt WV \& Pickard AR 1999 Role of reproductive technologies and genetic resource banks in animal conservation. Reviews in Reproduction 4 143-150.

Holt WV, Pickard AR, Abaigar T \& Cano M 2002 Integrated approaches to the establishment of genetic resource banks for endangered gazelles. Proceedings of the 9th International Symposium on Spermatology, Cape Town. pp 127-132. Eds G Van der Horst, D Franken, R Bornman, $\mathrm{T}$ Bornman \& S Dyer. Bologna: Monduzzi Editore.

Howard JG, Marinari PE \& Wildt DE 2003 Black-footed ferret: model for assisted reproductive technologies contributing to in situ conservation. In Reproductive Science and Integrated Conservation, pp 249-266. Eds WV Holt, AR Pickard, J Rodger \& DE Wildt. Cambridge: Cambridge University Press.

Humpherys D, Eggan K, Akutsu H, Hochedlinger K, Rideout WM 3rd, Biniszkiewicz D, Yanagimachi R \& Jaenisch R 2001 
Epigenetic instability in ES cells and cloned mice. Science 293 95-97.

International Union of Conservation of Nature and Natural Resources (IUCN) 2002 IUCN Red List of Threatened Species. http://www.redlist.org. Downloaded on 14 August 2002.

Johnston SD \& Holt WV 2001 Germplasm conservation in marsupials. In Cryobanking the Genetic Resource. Wildlife Conservation for the Future?, pp 203-225. Eds PF Watson \& WV Holt. London and New York: Taylor \& Francis.

Kleiman DG 1983 Ethology and reproduction of captive Giant Panda (Ailuropoda melanoleuca). Zeitschrift fur Tierpsychologie 62 1-46.

Lanza RP, Dresser BL \& Damiani P 2000 Cloning Noah's Ark. Scientific American 283 84-89.

Lee KY, Huang H, Ju B, Yang Z \& Lin S 2002 Cloned zebrafish by nuclear transfer from long-term cultured cells. Nature Biotechnology $20785-786$.

Meek J 2002 Scientists pledge to clone extinct Tasmanian tiger. The Guardian. Wednesday 29 May.

Mugnano JA, Costanzo JP, Beesley SG \& Lee RE Jr 1998 Evaluation of glycerol and dimethylsulfoxide for the cryopreservation of spermatozoa from the wood frog (Rana sylvatica). Cryoletters 19 249-254.

Paxton JR \& Eschmeyer WN 1998 Encyclopedia of Fishes. San Diego: Academic Press.

Pickard AR, Abaigar T, Green DI, Holt WV \& Cano M 2001 Hormonal characterization of the reproductive cycle and pregnancy in the female Mohor gazelle (Gazella dama mhorr). Reproduction $122571-580$.

Prather RS, Hawley RJ, Carter DB, Lai L \& Greenstein JL 2003 Transgenic swine for biomedicine and agriculture. Theriogenology $\mathbf{5 9}$ 115-123.

Reid GM \& Hall H 2003 Reproduction in fishes in relation to conservation. In Reproductive Science and Integrated Conservation, pp 374-393. Eds WV Holt, AR Pickard, J Rodger \& DE Wildt Cambridge: Cambridge University Press.

Renard JP, Zhou Q, LeBourhis D, Chavatte-Palmer P, Hue I, Heyman Y \& Vignon X 2002 Nuclear transfer technologies: between successes and doubts. Theriogenology 57 203-222.

Ryder OA 2002 Cloning advances and challenges for conservation. Trends in Biotechnology 20 231-232.

Ryder OA \& Benirschke K 1997 The potential use of 'cloning' in the conservation effort. Zoo Biology 16 295-300.

Shimozawa N, Ono Y, Kimoto S, Hioki K, Araki Y, Shinkai Y, Kono T \& Ito M 2002 Abnormalities in cloned mice are not transmitted to the progeny. Genesis 34 203-207.
Stone R 2001 Mammoth: the Resurrection of an Ice Age Giant. New York: Perseus Publishing.

Sutovsky P, Moreno RD, Ramalho-Santos J, Dominko T, Simerly C \& Schatten G 2000 Ubiquitinated sperm mitochondria, selective proteolysis, and the regulation of mitochondrial inheritance in mammalian embryos. Biology of Reproduction 63 582-590.

Swanson WF, Howard JG, Roth TL, Brown JL, Alvarado T, Burton M Starnes D \& Wildt DE 1996 Responsiveness of ovaries to exogenous gonadotropins and laparoscopic artificial-insemination with frozen-thawed spermatozoa in ocelots (felis-pardalis). Journal of Reproduction and Fertility 106 87-94.

Thorne ET \& Oakleaf B 1991 Species rescue for captive breeding: Black-footed ferret as an example. In Beyond Captive Breeding: Re-introducing Endangered Mammals to the Wild, pp 241-261. Ed. JHW Gipps. Oxford: Clarendon Press.

Wakamatsu Y, Ju B, Pristyaznhyuk I, Niwa K, Ladygina T, Kinishita M, Araki K \& Ozato K 2001 Fertile and diploid nuclear transplants derived from embryonic cells of a small laboratory fish, medaka (Oryzias latipes). PNAS 98 1071-1076.

Wakayama T \& Yanagimachi R 2001 Mouse cloning with nucleus donor cells of different age and type. Molecular Reproduction and Development 58 376-383.

Watson PF \& Holt WV 2001 Cryobanking the Genetic Resource. Wildlife Conservation for the Future? p 463. London and New York: Taylor \& Francis.

Wells DN 2000 Cloning for animal conservation. Cloning 2 $152-155$

Wells DN, Misica PM, Day TA \& Tervit HR 1997 Production of cloned lambs from an established embryonic cell line: a comparison between in vivo- and in vitro-matured cytoplasts. Biology of Reproduction 57 385-393.

Wilmut I, Schnieke AE, McWhir J, Kind AJ \& Campbell KH 1997 Viable offspring derived from fetal and adult mammalian cells. Nature 385 810-813.

Wolvekamp MCJ, Cleary ML, Cox SL, Shaw JM, Jenkin G \& Trounson AO 2001 Follicular development in cryopreserved common wombat ovarian tissue xenografted to nude rats. Animal Reproduction Science 65 135-147.

Yan SY 2000 A historical review and some comments on the nuclear transplantation in fish. Sheng $W u$ Gong Cheng Xue Bao 16 541-547.

Young LE \& Fairburn HR 2000 Improving the safety of embryo technologies: possible role of genomic imprinting. Theriogenology $\mathbf{5 3}$ 627-648. 